\title{
Synchrotron X-ray Imaging of Ion Transport in Unconventional Shales
}

\author{
VINCENT NOËL ${ }^{1}$, FLORENT BRONDOLO ${ }^{1}$, JENNIFER L. \\ DRUHAN $^{2}$, WENJIA FAN ${ }^{1}$, ADAM JEW ${ }^{1}$, ELEANOR \\ SPIELMAN-SUN ${ }^{1}$, ANTHONY KOVSCEK ${ }^{3}$, JOHN R. \\ BARGAR $^{1}$, AND GORDON E. BROWN, JR. ${ }^{1,3}$ \\ ${ }^{1}$ SLAC National Accelerator Lab, Menlo Park, CA, USA \\ ${ }^{2}$ University of Illinois, Urbana-Champaign, IL, USA \\ ${ }^{3}$ Stanford University, Stanford, CA, USA
}

Intrinsically, shale reservoirs have extremely low permeabilites (i.e. nano- to micro Darcys), making it difficult to produce hydrocarbons. Large quantities of freshwater are required during hydraulic fracturing $(\sim 32$ million $\mathrm{L}$ for each horizontal well), most coming from shallow aquifers and municipal supplies, resulting in the production of considerable quantities of hard-to-recycle highly saline waters, threatening watersheds, and increasing colloid formation and aggregation which can clog shale pores and pore necks. Although acidic hydraulic fracturing fluids (HFFs) may dissolve carbonates, pyrite, and other minerals to increase shale permeability/porosity and fluid transport, they also result in the formation of secondary mineral precipitation (e.g., barite, celestite, gypsum, iron oxides), which ultimately reduces permeability and transport. Our ability to understand the reactive behavior or shale in the presence of fluids rests on our understanding of ion diffusion in shales, which is nascent. In order to address these and related problems impacting the efficiency of hydrocarbon recovery, we have carried out a study of the interaction of acidic HFF with several unconventional shales (Marcellus, Wolfcamp, Barnett, Eagle Ford) with different mineralogies and types of organic matter.

In order to experimentally observe ion diffusion in shales, we tracked the penetration of acidic HFF, and the response of this imbibition on time-resolved selective ion diffusion and mineral transformations using a bromide tracer and synchrotron X-ray fluorescence mapping combined with nanoSIMS and compositional analysis of the HFF. Our results show that spontaneous penetration of acidic HFF and calcite dissolution occur at similar rates and consequently are intertwined, which suggests that imbibition is reactive. Conversely, our results clearly show that the presence of major carbonates inhibits acidic HFF diffusion. Finally, we show that in addition to the mineralogy of the shales, the fluid compositions, including dissloved $\mathrm{Ba}, \mathrm{pH}$, and ionic strength, can also significantly impacted the diffusivity of solutes. 